\title{
Crystallization and Beneficiation of Magnetite for Iron Recycling from Nickel Slags by Oxidation-Magnetic Separation
}

\author{
Yongbo Ma ${ }^{1,2}$, Xueyan $\mathrm{Du}^{1,2, *}$, Yingying Shen ${ }^{1,2}$, Guozhou $\mathrm{Li}^{1,2}$ and Ming $\mathrm{Li}^{1,2}$ \\ 1 State Key Laboratory of Advanced Processing and Recycling of Non-Ferrous Metals, \\ Lanzhou University of Technology, Lanzhou 730050, China; 62534abc@163.com (Y.M.); \\ shenyingying005@163.com (Y.S.); 15293189120@163.com (G.L.); lm_lut@163.com (M.L.) \\ 2 School of Materials Science and Engineering, Lanzhou University of Technology, Lanzhou 730050, China \\ * Correspondence: duxy@lut.cn; Tel.: +86-931-297-3961
}

Received: 22 June 2017; Accepted: 18 August 2017; Published: 22 August 2017

\begin{abstract}
The iron resources in nickel slag were recycled by oxidation and magnetic separation. The effects of holding time, temperature, air flow rate and basicity on the crystallization of magnetite were investigated systematically. Moreover, the influence of particle size and magnetic flux density on the recovery and grade of iron during the magnetic separation was also explored. Results showed that the magnetite particles were significantly influenced by holding time, and the average diameter size reached about $20 \mu \mathrm{m}$ after holding for $20 \mathrm{~min}$ at $1623 \mathrm{~K}$. The holding temperature obviously affected the microstructure of magnetite phases: with the increase in holding temperature, the shapes of the magnetite particles changed from polyhedral form to skeletal particles. As the air flow rate was increased to $170 \mathrm{~mL} / \mathrm{min}$, the magnetite developed into tiny spherical particles due to the strong stirring. It was also found that the crystallization of magnetite was slightly effected by basicity. The iron recovery reduced with the decrease of particle size, while the iron grade first increased to a maximal value of $38 \mu \mathrm{m}$, and then decreased. As the magnetic flux density increased, the iron recovery initially increased rapidly, reaching a maximal value at $120 \mathrm{mT}$, while the iron grade remained almost constant. The final iron recovery and grade were $75.99 \%$ and $54.08 \%$, respectively, via multi-step magnetic separation instead of single magnetic separation. Iron in concentrate mainly exists in the form of magnetite and magnesium ferrite, and contents of siderophile elements $(\mathrm{Ni}, \mathrm{Co})$ in final concentrate were also higher than that of raw slags.
\end{abstract}

Keywords: nickel slag; oxidation; crystallization; beneficiation; magnetite; magnetic separation

\section{Introduction}

Due to the high content of iron (about 36-45 wt \% [1]) and value-added metals, such as Ni, Co, $\mathrm{Cu}$, iron-rich nickel slag can be considered to be an important secondary source of metals, especially for iron ore. As yet, the only way to recover iron from nickel slag efficiently is by reduction-magnetic separation [2-4]. In this process, coke or coal is used to reduce fayalite $\left(\mathrm{Fe}_{2} \mathrm{SiO}_{4}\right)$ in nickel slag, while producing iron and silicates; $\mathrm{CaO}$ is also added to improve the reaction rate by destroying the structure of the silicates. However, several disadvantages of this method have limited its industrial applications: (1) the inevitable emission of $\mathrm{CO}$ and $\mathrm{CO}_{2} ;(2)$ the difficulty of removal of impure elements, such as $\mathrm{Pb}$, $\mathrm{Zn}$, and As, which are simultaneously reduced and are harmful to the subsequently steel production; and (3) the severe uncontrollability and large quantities of $\mathrm{CaO}$ addition.

Therefore, an environmentally friendly method for iron recycling from slags by an oxidation process has prompted wide attention. Numerous scholars have studied the oxidation of the iron-bearing phase in slag systems. Semykina [5] presented the kinetics of the oxidation of divalent 
iron to a trivalent state in liquid $\mathrm{FeO}-\mathrm{CaO}-\mathrm{SiO}_{2}$ slags. Zhang [6] studied the oxidation mechanism of $\mathrm{CaO}-\mathrm{FeOx}-\mathrm{SiO}_{2}$ slag with high iron content in a pure oxygen atmosphere. The crystal growth during oxidation of a liquid $\mathrm{FeO}-\mathrm{CaO}-\mathrm{SiO}_{2}$ slag was shown in the research work of Semykina [7]. Fan [8] reported the crystallization behavior of copper smelter slag during molten oxidation. Liu [9] analyzed the multiphase transformation during the copper slag calcination process.

Magnetic separation has been applied to separate the iron-bearing minerals from metallurgical slags. Zhang [10] studied the recovery of iron from waste pyrite slag by using magnetic separation after reduction roasting. Peng [11] reported the recovery of iron from zinc ferrite $\left(\mathrm{ZnFe}_{2} \mathrm{O}_{4}\right)$ undergoing reduction roasting via magnetic separation. Two-step magnetic separation was used to recover magnetite from red mud by Li [12].

Although the oxidation of iron-bearing phases in metallurgical slags have been studied [5-8,13], few reports about the influence of factors on the crystallization of magnetite phases in nickel slag were available. In this work, holding time, temperature, air flow rate, basicity, particle size and magnetic flux were adjusted to study their influence on the crystallization behavior and beneficiation of magnetite phases, attempting to provide a scientific basis for the recovery of iron sources from nickel slags.

\section{Materials and Methods}

\subsection{Experimental Materials}

Water-quenched nickel slag, appearing as ash black spherical particles $(<5 \mathrm{~mm})$, were taken from a nickel flash furnace in Jinchuan Group Ltd. (Jinchang, China); its composition is given in Table 1. The total iron content accounted for approximately $40 \%$ of the material, which also contained some valuable metals including $\mathrm{Ni}, \mathrm{Co}$, and $\mathrm{Cu}$. The raw slag mainly consisted of fayalite, resulting in the X-ray diffraction patterns in Figure 1. The elemental scanning maps showed the $\mathrm{Fe}, \mathrm{Si}, \mathrm{Mg}$ and Ca distributed uniformly in slags, indicating that iron was hard to be recovered via conventional separation methods.

Table 1. Compositions of nickel slag (wt \%).

\begin{tabular}{ccccccccccc}
\hline Fe & Si & Mg & Ca & S & Ni & Co & $\mathbf{C u}$ & Pb & Zn & As \\
\hline 39.19 & 20.14 & 5.07 & 2.56 & 1.20 & 0.16 & 0.08 & 0.22 & 0.01 & 0.05 & 0.00048 \\
\hline
\end{tabular}

Calcium oxide $(\mathrm{CaO})$ powder with a purity of $99.9 \%$, supplied by Damao chemical reagents Co., Ltd. (Tianjin, China), was employed as the modifier. Alumina crucibles for holding the slags were of $99.99 \%$ purity, and were $50 \mathrm{~mm}$ in diameter, $80 \mathrm{~mm}$ in height, and $1 \mathrm{~mm}$ in thickness.
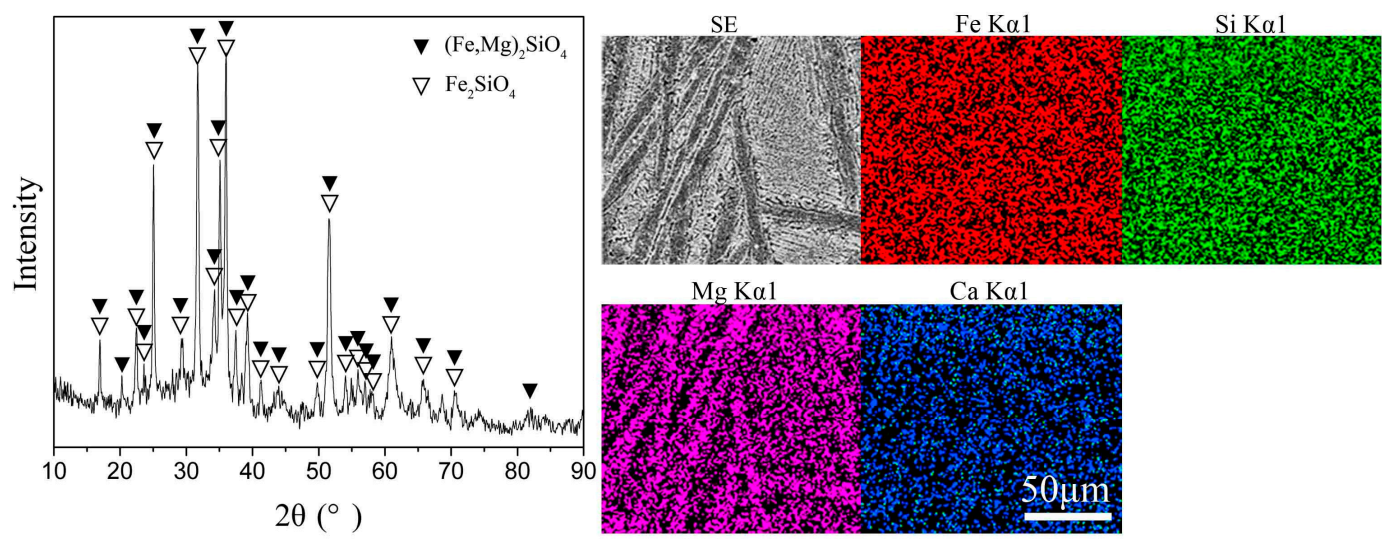

Figure 1. XRD patterns and elemental scanning maps of water-quenched nickel slag. 


\subsection{Equipmental and Analytical Method}

MobileLab Workstation, including a muffle furnace (Tangshan nano source microwave thermal instrument manufacturing Co., Ltd., Tangshan, China), was used to heat and control the temperature. The nickel slags were crushed to a specific size via a grinder (QM-3SP04, Yongsheng mineral equipment manufacturing Co., Ltd., Ganzhou, China). The magnetic separation was performed by a wet feebleness magnetic-separation machine (XCGQ-50, Tangshan Shida automation instrumentation technology Co., Ltd., Tangshan, China) with a maximum flux of $350 \mathrm{mT}$.

X-ray diffraction (XRD) measurements were performed on a diffractometer (D/Max 2400, Rigaku, Tokyo, Japan), and a scanning electron microscope (SEM) equipped with an energy dispersive spectrometer (SU-6600, Hitachi, Tokyo, Japan) was used to analyze the microstructure and elemental distribution. The magnetic properties of samples were tested using a vibrating sample magnetometer (VSM) (LakeShore 7304, Lake Shore Cryotronics, Inc., Westerville, OH, USA). Compositions of the samples were analyzed by ICP (ICAP-7400, Thermo Scientific, Logan, UT, USA).

\subsection{Experimental Procedure}

The molten oxidation process was carried out in a microwave muffle furnace in the MobileLab Workstation. The whole treatment process is shown in Figure 2. Firstly, the nickel slag particles were crushed to $-180 \mu \mathrm{m}$ ( 80 mesh), and then mixed with $\mathrm{CaO}$ in various specific proportions. Secondly, the mixture, placed into an alumina crucible and located in the center of the furnace, was heated in air to the target temperature at a rate of $5 \mathrm{~K} / \mathrm{min}$. Subsequently the air from a compressor was blown into the molten slags through an alumina tube at various rates. After a certain holding duration, the sample was cooled to room temperature in air at a rate of $5 \mathrm{~K} / \mathrm{min}$. Finally, the oxidized nickel slags (ONS) were crushed into powders and magnetic separation was performed at various magnetic flux densities.

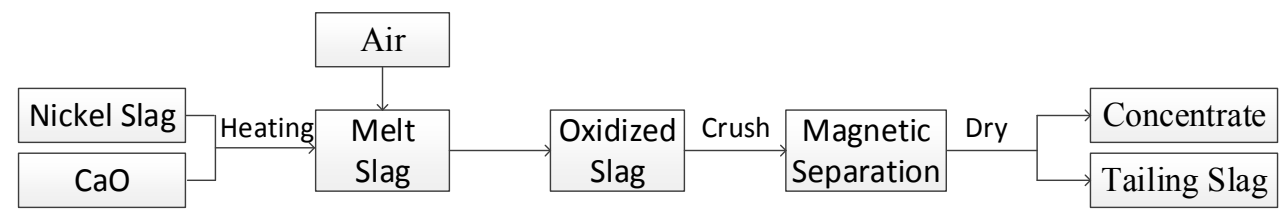

Figure 2. The flowsheet of the oxidation and separation process.

\section{Results and Discussion}

\subsection{Thermodynamic Feasibility Analysis}

It is well known from Molecular theory that molten slag is made up of electroneutral simple oxides and combined oxides. The two kinds of oxides are dynamically balanced under certain conditions, and only free oxide can participate in the reactions with other groups in the slag. So the primary reactions in this study are shown to be the following:

$$
\begin{gathered}
\mathrm{Fe}_{2} \mathrm{SiO}_{4}=2 \mathrm{FeO}+\mathrm{SiO}_{2} \\
\mathrm{Fe}_{2} \mathrm{SiO}_{4}+\mathrm{CaO}=2 \mathrm{FeO}+\mathrm{CaSiO}_{3} \\
6 \mathrm{FeO}+\mathrm{O}_{2}=2 \mathrm{Fe}_{3} \mathrm{O}_{4} \\
4 \mathrm{FeO}+\mathrm{O}_{2}=2 \mathrm{Fe}_{2} \mathrm{O}_{3} \\
3 \mathrm{Fe}_{2} \mathrm{SiO}_{4}+\mathrm{O}_{2}=2 \mathrm{Fe}_{3} \mathrm{O}_{4}+3 \mathrm{SiO}_{2} \\
3 \mathrm{Fe}_{2} \mathrm{SiO}_{4}+3 \mathrm{CaO}+\mathrm{O}_{2}=2 \mathrm{Fe}_{3} \mathrm{O}_{4}+3 \mathrm{CaSiO}_{3} \\
4 \mathrm{Fe}_{3} \mathrm{O}_{4}+\mathrm{O}_{2}=6 \mathrm{Fe}_{2} \mathrm{O}_{3}
\end{gathered}
$$


The Gibbs free energy of the above reactions from $273 \mathrm{~K}$ to $1873 \mathrm{~K}$ was calculated using HSC Chemistry 5.11 software (Outotec, Espoo, Finland), and the relationship between Gibbs free energy and temperature is shown in Figure 3. It can be seen that the fayalite phase cannot decompose below $1873 \mathrm{~K}$. The fayalite has a greater tendency to react with oxygen due to the addition of $\mathrm{CaO}$. The free $\mathrm{FeO}$, which was replaced from fayalite by $\mathrm{CaO}$, can react with oxygen to produce hematite and magnetite, and the latter is much more easily formed. Magnetite may be oxidized by the excessive oxygen, but that seems not to happen when temperature is higher than $1623 \mathrm{~K}$.

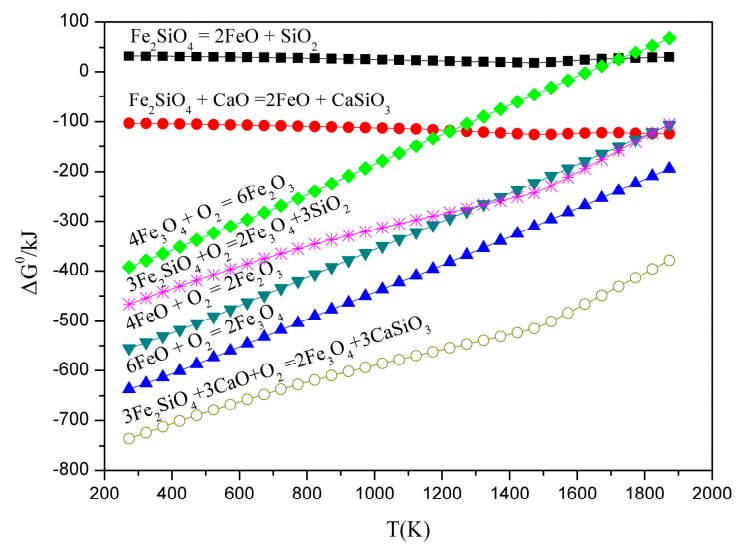

Figure 3. Relationship between $\Delta \mathrm{G}^{0}$ and temperature.

In order to investigate the role of temperature and $\mathrm{CaO}$ in the oxidation process, liquidus projections of $\mathrm{FeO}-\mathrm{SiO}_{2}-\mathrm{MgO}-\mathrm{CaO}-\mathrm{O}_{2}$ with different $\mathrm{CaO}$ addition were calculated by FactSage 7.1 (Thermfact/CRCT, Montreal, Canada; GTT-Technologies, Aachen, Germanyt), as shown in Figure 4. It was found that the spinel-structured magnetite formed a narrow low melting zone $(1673 \mathrm{~K})$ without $\mathrm{CaO}$ addition. But with increasing addition of $\mathrm{CaO}$, both this zone and the spinel phase zone obviously expanded, and a lower liquidus zone (1573 K) and hematite phase occurred simultaneously when the addition of $\mathrm{CaO}$ was about $10 \%$. If the addition of $\mathrm{CaO}$ was increased to $15 \%$, both the $1573 \mathrm{~K}$ zone and hematite zone expanded, while the spinel phase zone shrunk, but the spinel zone at $1573 \mathrm{~K}$ barely changed. This means a moderate $\mathrm{CaO}$ addition can not only expand the spinel phase zone, but also decrease the liquidus temperature of the slag.

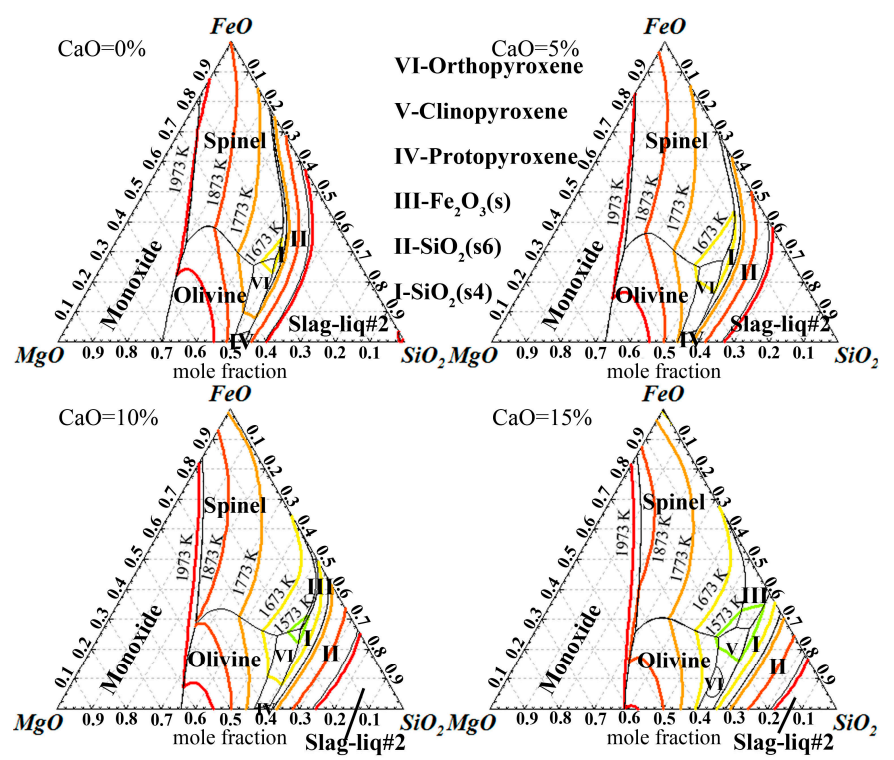

Figure 4. Liquidus projections of $\mathrm{FeO}-\mathrm{SiO}_{2}-\mathrm{MgO}-\mathrm{CaO}-\mathrm{O}_{2}$ with various levels of $\mathrm{CaO}$ addition. 
Therefore, the addition of $\mathrm{CaO}$ can help oxidation and produces spinel structured magnetite at a lower temperature in $\mathrm{FeO}-\mathrm{SiO}_{2}-\mathrm{MgO}-\mathrm{CaO}-\mathrm{O}_{2}$ system slag.

\subsection{Influence Factors on the Crystallization of Magnetite}

After oxidation, the fayalite phase changed mainly into magnetite phase, as shown in Figure 5, which was in good agreement with the results of thermodynamic analysis. In order to control the growth of magnetite phase and obtain larger particles, further studies on the crystallization of magnetite were subsequently systematically performed.
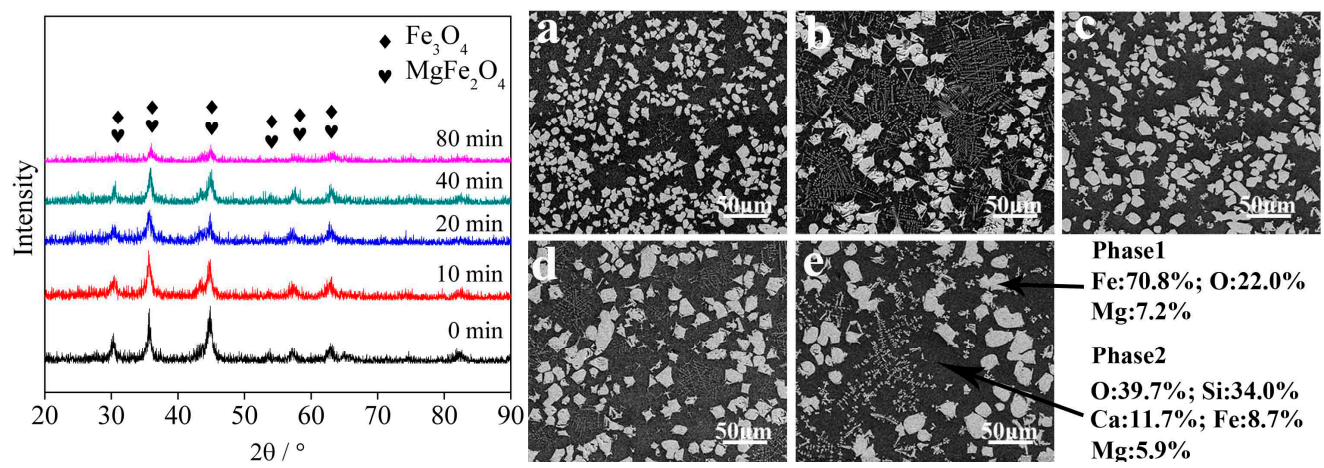

Figure 5. XRD patterns and SEM images of water-quenched samples held for various times. (a) 0 min; (b) $10 \mathrm{~min}$; (c) $20 \mathrm{~min}$; (d) $40 \mathrm{~min}$; (e) $80 \mathrm{~min}$.

\subsubsection{Holding Time}

Figure 5 shows that iron in ONS mainly existed as magnetite and magnesium ferrite after being oxidized in air. The average diameter of magnetite particles was about $10 \mu \mathrm{m}$ when the temperature reached $1623 \mathrm{~K}$. The diameter of the particles, accompanied by some tiny particles, increased to $20 \mu \mathrm{m}$ when the holding time was $20 \mathrm{~min}$, while the crystal size grew slightly when the holding time was longer than $20 \mathrm{~min}$. This result was similar to the findings for oxidation of $\mathrm{FeO}-\mathrm{CaO}-\mathrm{SiO}_{2}$ slag systems [7].

\subsubsection{Temperature}

It can be seen from Figure 6 that the temperature obviously affected the microstructure of magnetite phases. Similar results appeared in the molten oxidation of copper slags, which was attributed to the phase transition of magnetite to hematite [8]. Indeed, the microstructure of magnetite depended upon the interface and preferred orientation. Even though the greater viscosity at lower temperatures was unfavorable to the diffusion of components and deteriorated the condition of crystallization, the fully growed magnetite particles was able to compensate for these imperfections. Thus, tiny spherical particles and polyhedral grains formed under these conditions. The spherical magnetite could be attributed to Oswald ripening, while the angular grains resulted from unstable growth.

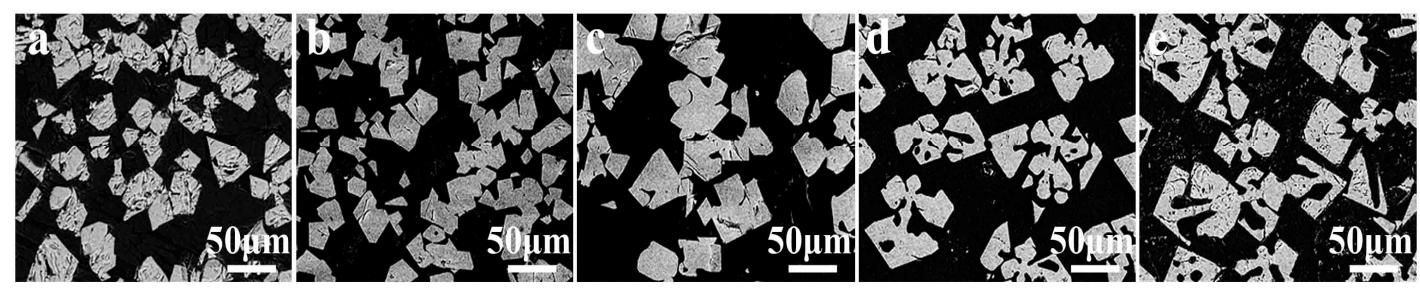

Figure 6. SEM images of cooled samples after treatment at different holding temperatures. (a) $1623 \mathrm{~K}$; (b) $1673 \mathrm{~K}$; (c) $1723 \mathrm{~K}$; (d) $1773 \mathrm{~K}$; (e) $1823 \mathrm{~K}$. 
It was also found that the micro-structure of magnetite changed into a skeletal structure when the temperature was higher than $1723 \mathrm{~K}$. This could be primarily attributed to the preferred orientation and rapid growth at higher temperatures.

\subsubsection{Air Flow Rate}

Lower air flow rate provided a weaker stirring, resulting in homogeneous crystallization of magnetite particles, and producing many spherical particles or polyhedral grains. If the air flow rate was higher than $170 \mathrm{~mL} / \mathrm{min}$, the violent stirring was able to break the dendrites and cause the production of tiny crystal. The produced tiny particles were able to embed into silicate in other areas due to Oswald ripening, as shown in Figure 7.

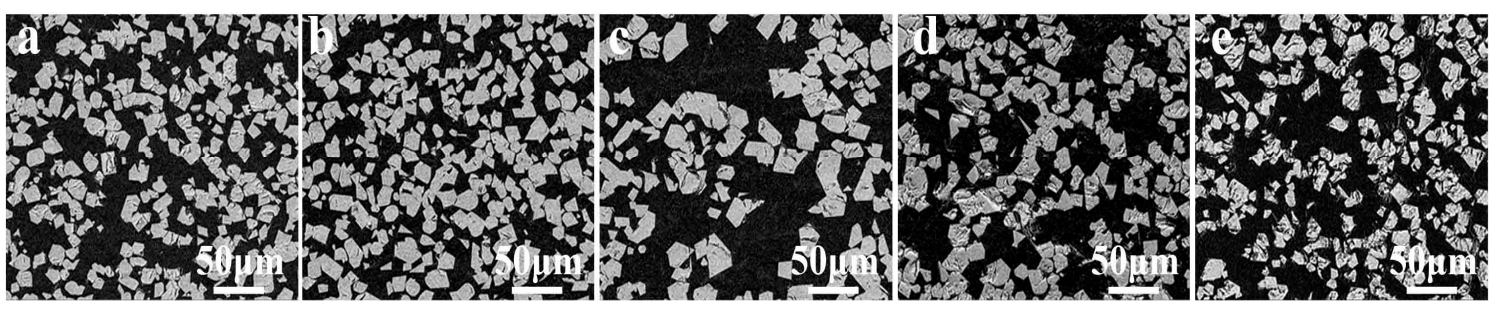

Figure 7. SEM images of cooled samples at various air flow rate. (a-e) show 140, 155, 170, 185 and $200 \mathrm{~mL} / \mathrm{min}$, respectively.

\subsubsection{Basicity}

As a modifier, $\mathrm{CaO}$ plays an activation role in the oxidation process and changes the basicity of nickel slags. Generally, $\mathrm{CaO}$ is mainly used to enhance the reaction, i.e., Equation (6), between fayalite and oxygen by destroying the structure of fayalite. The basicity in this work can be described as $[\mathrm{w}(\mathrm{CaO})+\mathrm{w}(\mathrm{MgO})] / \mathrm{w}\left(\mathrm{SiO}_{2}\right)$. The basicity was $0.6,0.7,0.8,0.9$ and 1.0, for added proportions of $\mathrm{CaO}$ of $7.4 \%, 10.5 \%, 13.7 \%, 16.9 \%$ and $20.0 \%$, respectively.

It can be seen from Figure 8 that the morphology of magnetite particles remained very similar with the increase of amount of added $\mathrm{CaO}$, implying that the addition of $\mathrm{CaO}$ may have little influence on the crystallization of magnetite. In addition, the raw slags could not be melted until the temperature reached $1603 \mathrm{~K}$, and a temperature higher than $1623 \mathrm{~K}$ was also required by slags with a basicity of 0.5 . However, liquid phase occurred before $1623 \mathrm{~K}$ when the basicity was increased to 0.6 . This means that the liquidus temperature of the slags seems to decrease with the increase of $\mathrm{CaO}$ addition, as reported in the literature [4].

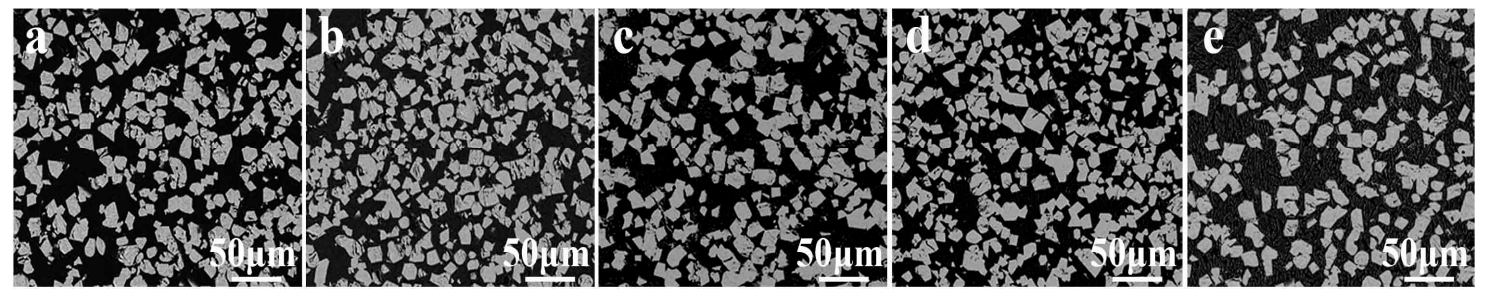

Figure 8. SEM images of cooled samples at various basicity. (a) 0.6 ; (b) 0.7 ; (c) 0.8 ; (d) 0.9 ; (e) 1.0 .

\subsection{Magnetic Separation}

It can be concluded from the above studies that the iron-bearing samples consisted of mainly magnetite and magnesium ferrites. Because of their excellent magnetic properties, they can be separated from slags by using of magnetic separation. Research $[10,14]$ has already proved that magnetic separation is an effective way to concentrate iron resources. 
The index of beneficiation, such as yield of concentrates and iron recovery, can be calculated as follows:

$$
\begin{gathered}
\gamma_{\mathrm{n}}=\mathrm{m}_{\text {concentrate, } \mathrm{n}} / \mathrm{m}_{\text {concentrate, } \mathrm{n}-1} \times 100 \% \\
\varepsilon_{\mathrm{n}}=\gamma \times \mathrm{w}_{\text {iron, } \mathrm{n}} / \mathrm{w}_{\text {iron, } \mathrm{n}-1}
\end{gathered}
$$

where $\gamma_{\mathrm{n}}, \mathrm{m}_{\text {concentrate, } \mathrm{n}}$ and $\mathrm{w}_{\text {iron, } \mathrm{n}}$ are the yield, mass and iron grade, respectively, of concentrate separated $\mathrm{n}$ times; if $\mathrm{n}=1, \mathrm{~m}_{\text {concentrate, }, 0}$ and $\mathrm{w}_{\mathrm{iron}, 0}$ presents for the mass and iron grade of ONS; $\varepsilon$ is the recovery of iron.

After the samples were crushed and ground into particles with a size of $-74 \mu \mathrm{m}$, the powders were underwent magnetic separation with a magnetic flux density of $300 \mathrm{mT}$. Influence of factors on the iron recovery and grade are shown in Figure 9, while the magnetic flux density and particle size were $300 \mathrm{mT}$ and $-74 \mu \mathrm{m}$, respectively. It can be seen that the iron recovery varied regularly, while the iron grade changed irregularly, and temperature was a significant influence factor that affected iron recovery due to the formation of different micro-structures, such as spherical, polyhedral and skeletal structures, as shown in Figure 6. Generally, the samples were crushed or ground into small particles before magnetic separation. After the grinding process, the skeletal particles accompanied with silicate could only be extracted incompletely, due to their weak magnetic property, causing a decrease in iron recovery. In contrast, the spherical and polyhedral particles could be extracted more completely, and, accordingly, a higher iron recovery could be obtained due to their uniform and regular shapes, i.e., a higher degree of mineral liberation. Therefore, spherical and polyhedral particles were conducive to the magnetic separation.
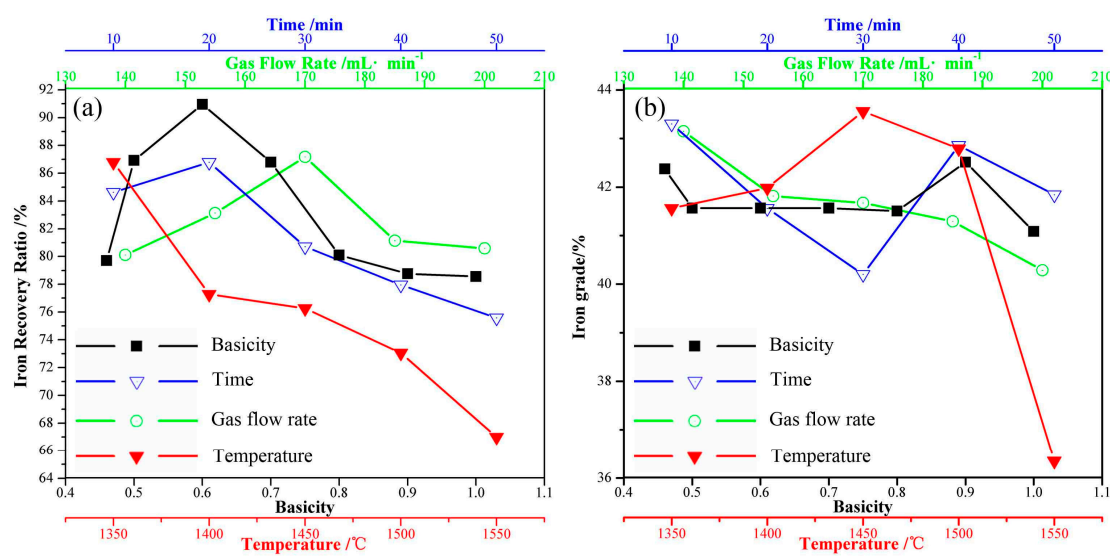

Figure 9. Effect of different factors on the iron recovery (a) and grade (b).

In order to explore the reasons for this change, the sample with the highest iron recovery was selected to perform SEM observation; its elemental scanning mappings are given in Figure 10. It was found that the sample contained not only Fe element, but $\mathrm{Ni}, \mathrm{Co}, \mathrm{Mg}, \mathrm{Cu}, \mathrm{Si}$ and $\mathrm{Ca}$ elements, implying that iron grade was at a low level (about $42 \%$ ). Therefore, it was necessary to research the influence factors on magnetic separation in more detail.

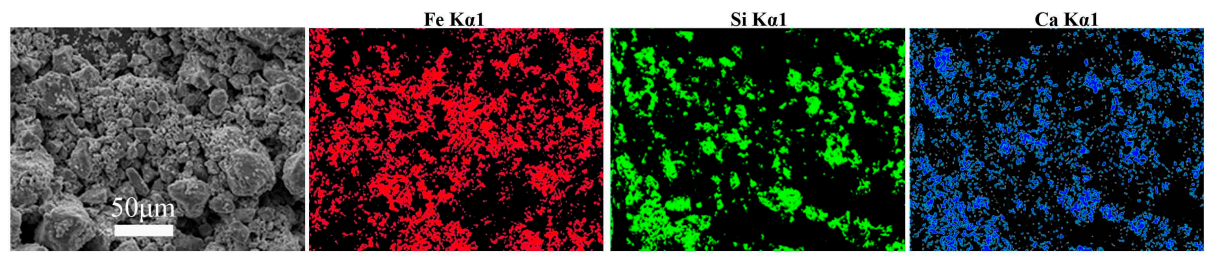

Figure 10. Cont. 

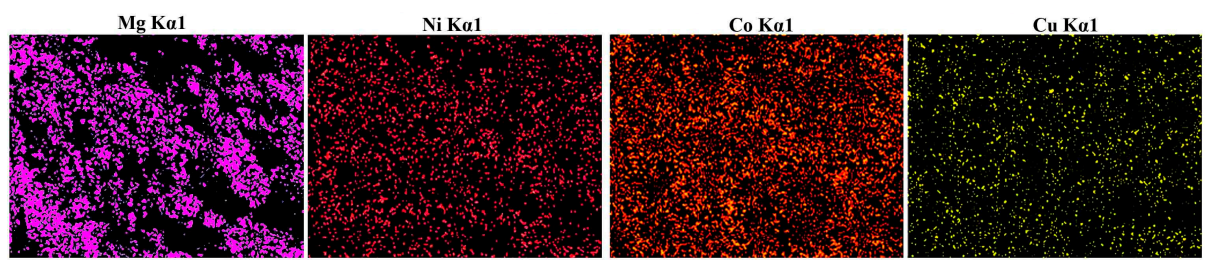

Figure 10. SEM images and elemental scanning maps of the sample separated once.

\subsubsection{Particle Size}

It is well known that particle size is an important factor in magnetic separation. Therefore, the relationship between iron recovery, iron grade and particle size was studied in detail.

It can be seen from Figure 11a that with decreasing particle size, the iron recovery decreased gradually, while the iron grade firstly increased to a maximal value at $38 \mu \mathrm{m}$, and then decreased. This might mainly be attributed to the liberation degree of magnetite, and result from the combination of magnetite and augite. Figure 12a shows the saturation magnetization value of various particle sizes, implying $-38 \mu \mathrm{m}$ particles can be easily separated, and accordingly cause the maximal value of iron grade. Meanwhile, the abandoned augite particles inevitably carry off some magnetite particles during the separation, so the iron recovery exhibits a linearly declining tendency. As the particle size was smaller than $38 \mu \mathrm{m}$, it was difficult to separate magnetite particles, because of the magnetic action in the given magnetic field. Moreover, the fine magnetic particles reunited as clusters easily, which prevented the non-magnetic silicate from being removed. Ku's work [15] also proved that the fine magnetic particles have a tendency to assemble chains.
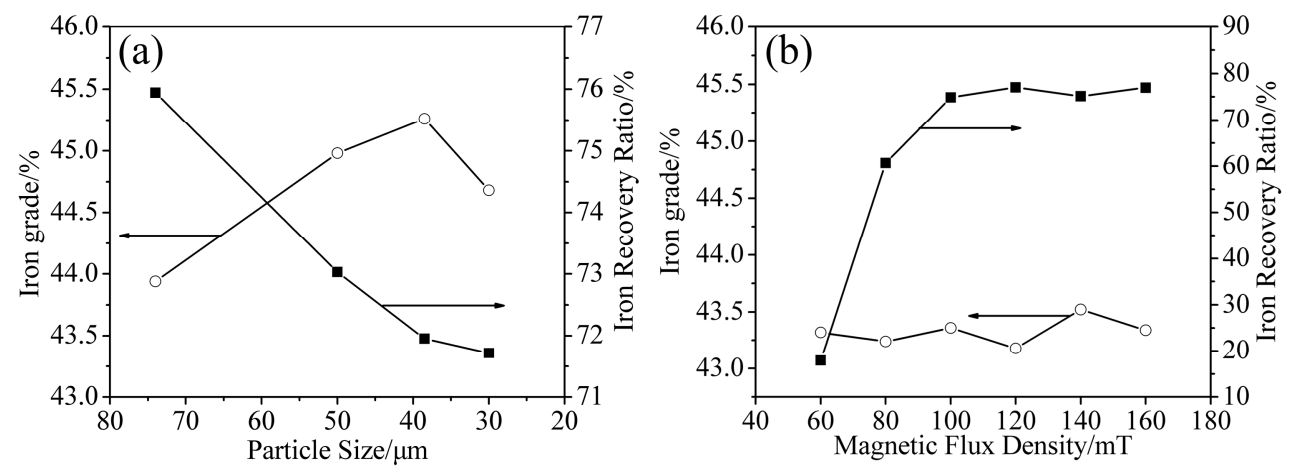

Figure 11. Effect of particle size (a) and magnetic flux density (b) on iron recovery and grade.
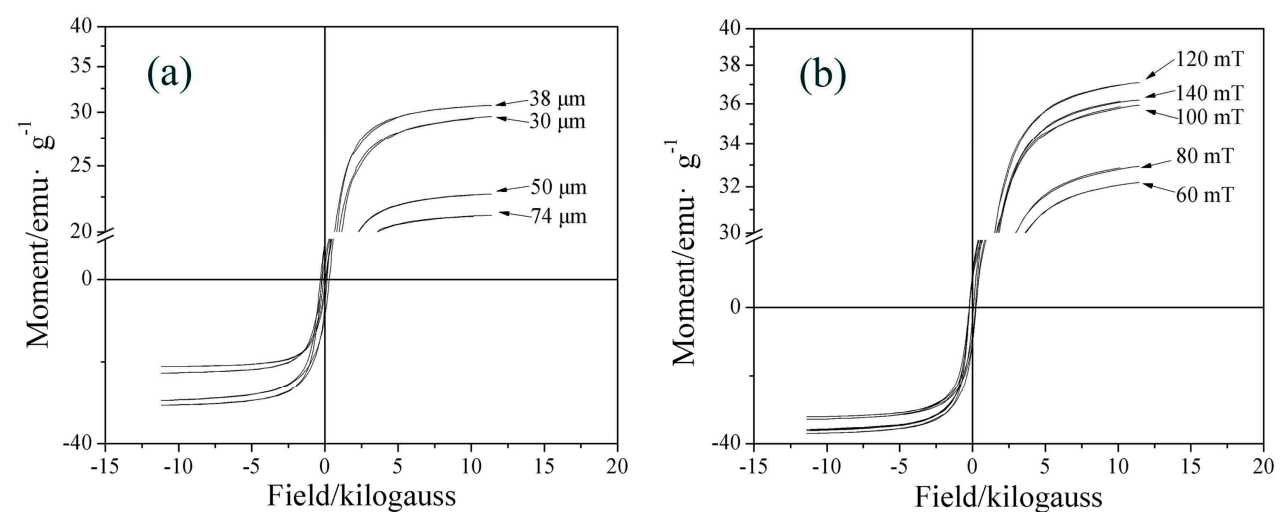

Figure 12. Effect of particle size (a) and magnetic flux density (b) on saturation magnetization. 


\subsubsection{Magnetic Flux Density}

The magnetic flux density is another influence factor on the magnetic separation. With lower magnetic flux density, ferromagnetic minerals, such as magnetite and magnesium ferrite, can be separated easily. Higher magnetic flux density is used to separate the paramagnetic minerals from the surrounding gangue.

As shown in Figure 11b, the iron recovery increased with the increase of magnetic flux density in the range of 60-120 $\mathrm{mT}$, while the iron grade remained almost constant. This can be ascribed mainly to the overgrinding and lower liberation degree of magnetite. In other words, the fine particles tended to go into the tailings when the magnetic flux was lower than $120 \mathrm{mT}$, due to the weaker magnetic force. If the magnetic flux was higher than $120 \mathrm{mT}$, the iron recovery seemed to reach a saturation value, implying that the tiny magnetite particles were separated completely. The iron grade was almost constant in the range of $60-160 \mathrm{mT}$, which was caused by the high liberation degree of magnetite. Figure $12 \mathrm{~b}$ shows the value of saturation magnetizations, from which we found that $120 \mathrm{mT}$ was the highest among the various fluxes.

\subsubsection{Optimal Conditions}

It can be concluded that the iron recovery increased obviously with a change in external factors, while the iron grade improved slightly. Therefore, multi-step magnetic separation, instead of single magnetic separation, was adopted to improve the iron grade. The separation process and the corresponding results are shown in Figure 13. The final iron recovery and grade reached $75.99 \%$ and $54.08 \%$, respectively, as shown in Table 2. It is worth mentioning that the contents of siderophile elements $(\mathrm{Ni}, \mathrm{Co})$ in the final concentrate were higher than that of raw slags, as shown in Table 3.

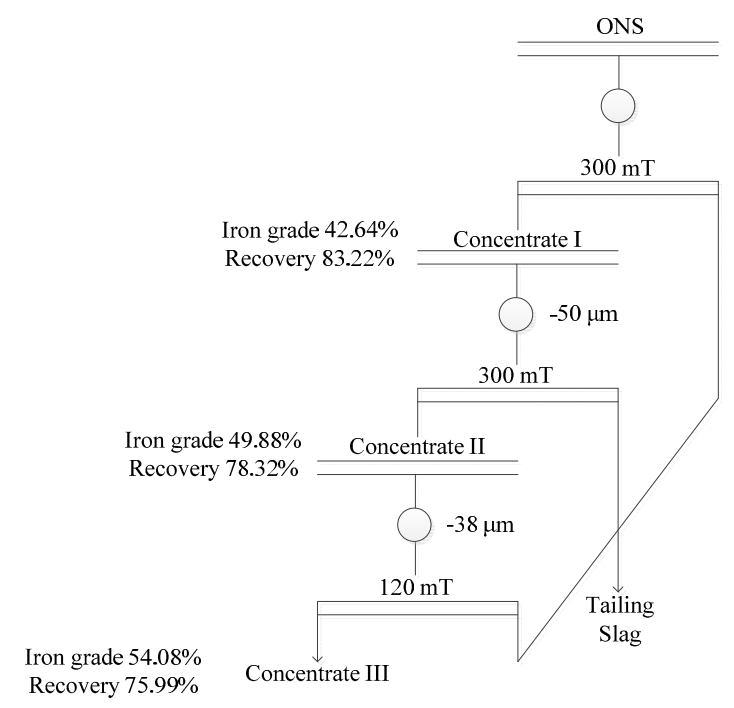

Figure 13. Flowsheet of magnetic separation for ONS.

Table 2. Iron grade, yield and recovery of concentrates (wt \%).

\begin{tabular}{lccccc}
\hline \multirow{2}{*}{ Products } & \multirow{2}{*}{ Iron Grade } & \multicolumn{2}{c}{ Yield } & \multicolumn{2}{c}{ Recovery } \\
\cline { 3 - 6 } & & Individual & Cumulative & Individual & Cumulative \\
\hline Concentrate I & 42.64 & 70.39 & 70.39 & 83.22 & 83.22 \\
Concentrate II & 49.88 & 80.45 & 56.63 & 94.11 & 78.32 \\
Concentrate III & 54.08 & 89.48 & 50.67 & 97.02 & 75.99 \\
\hline
\end{tabular}


Table 3. Compositions of concentrates and tailing slag (wt \%).

\begin{tabular}{ccccccccccc}
\hline Products & TFe & Si & Mg & Ca & Ni & Co & $\mathbf{C u}$ & $\mathbf{P b}$ & $\mathbf{Z n}$ & As \\
\hline Concentrate I & 42.64 & 8.83 & 4.81 & 3.20 & 0.18 & 0.10 & 0.21 & 0.002 & 0.040 & $<0.001$ \\
Concentrate II & 49.88 & 7.42 & 4.66 & 2.48 & 0.20 & 0.12 & 0.23 & 0.001 & 0.049 & $<0.001$ \\
Concentrate III & 54.08 & 5.04 & 3.15 & 0.82 & 0.21 & 0.12 & 0.24 & 0.005 & 0.049 & $<0.001$ \\
Tailing slag & 18.71 & 20.26 & 5.64 & 7.03 & 0.06 & 0.04 & 0.14 & 0.015 & 0.05 & $<0.001$ \\
\hline
\end{tabular}

\section{Conclusions}

(1) It can be seen from the thermodynamic analysis that fayalite in nickel slag cannot be decomposed spontaneously, even with temperatures of up to $1873 \mathrm{~K}$, but can be oxidized into magnetite with the help of $\mathrm{CaO}$ and $\mathrm{O}_{2}$. Liquidus projection of $\mathrm{FeO}-\mathrm{SiO}_{2}-\mathrm{MgO}-\mathrm{CaO}-\mathrm{O}_{2}$ shows that the addition of $\mathrm{CaO}$ can not only expand the spinel phase zone, but also obviously decrease the liquidus temperature.

(2) Fayalite in nickel slags can be oxidized to form magnetite phase in air at high temperature. The holding time, temperature, and air flow rate significantly affect the crystallization behavior of magnetite, while the addition of $\mathrm{CaO}$ affects it slightly. The average diameter size of the magnetite reaches $20 \mu \mathrm{m}$ after undergoing a holding process at $1623 \mathrm{~K}$ for $20 \mathrm{~min}$. Temperature and air flow rate obviously affect the shapes of magnetite, which exhibits spherical, polyhedral and skeletal shapes.

(3) The iron recovery and grade are obviously affected by particle size and magnetic flux density. The iron recovery decreases with the decrease of particle size, while the iron grade reaches a maximal value at $38 \mu \mathrm{m}$. As the magnetic flux density increases, the iron recovery initially increases rapidly, reaching a maximal value at $120 \mathrm{mT}$, while the iron grade remains almost constant.

(4) The final iron recovery and grade reaches $75.99 \%$ and $54.08 \%$, respectively, via multi-step magnetic separation, instead of single magnetic separation. Iron in the concentrate mainly exists in the form of magnetite and magnesium ferrite; and the contents of siderophile elements ( $\mathrm{Ni}, \mathrm{Co})$ in the final concentrate were also higher than that of the raw slags.

Acknowledgments: This work was financially supported by Science and Technology Major Project Plan of Gansu Province; the authors wish to express their thanks for the sponsorship. The fellowship for Ma Yongbo from LUT is also gratefully acknowledged.

Author Contributions: Yongbo Ma, Xueyan Du and Yingying Shen conceived and designed the experiments; Yongbo Ma and Guozhou Li performed the experiments; Yongbo Ma and Ming Li analyzed the data; Xueyan Du contributed reagents/materials/analysis tools; Yongbo Ma wrote the paper.

Conflicts of Interest: The authors declare no conflict of interest. The founding sponsors had no role in the design of the study; in the collection, analyses, or interpretation of data; in the writing of the manuscript, and in the decision to publish the results.

\section{References}

1. Jones, R.T. Economic and environmentally beneficial treatment of slags in DC arc furnaces. In Proceedings of the VII International Conference on Molten Slags, Fluxes and Salts, Cape Town, South Africa, 25-28 January 2004.

2. Pan, J.; Zheng, G.L.; Zhu, D.Q.; Zhou, X.L. Utilization of nickel slag using selective reduction followed by magnetic separation. Trans. Nonferrous Met. Soc. China 2013, 11, 3421-3427. [CrossRef]

3. Ni, W.; Ma, M.S.; Wang, Y.L.; Wang, Z.J.; Liu, F.M. Thermodynamic and kinetic in recovery of iron from nickel residue. J. Univ. Sci. Technol. B 2009, 2, 163-168.

4. Jin, Y.; Wang, W.Z.; Zhang, C.M. Research the kinetic of abstracting iron from Jin Chuan waste slag. In Proceedings of the VII National Conference on Metallurgical Reaction Engineering, Shenyang, China, 15-19 May 1998. 
5. Semykina, A.; Shatokha, V.; Iwase, M.; Seetharaman, S. Kinetics of oxidation of divalent iron to trivalent state in liquid FeO-CaO-SiO 2 slags. Metall. Mater. Trans. B 2010, 12, 1230-1239. [CrossRef]

6. Zhang, L.N.; Zhang, L.; Wang, M.Y.; Sui, Z.T. Oxidization mechanism in $\mathrm{CaO}-\mathrm{FeO}-\mathrm{SiO}_{2}$ slag with high iron content. Trans. Nonferrous Met. Soc. China 2005, 4, 938-943.

7. Semykina, A.; Nakano, J.; Sridhar, S.; Shatokha, V.; Seetharaman, S. Confocal scanning laser microscopy studies of crystal growth during oxidation of a liquid FeO-CaO-SiO 2 slag. Metall. Mater. Trans. B 2011, 6, 471-476. [CrossRef]

8. Fan, Y.; Shibata, E.; Iizuka, A.; Nakamura, T. Crystallization behavior of copper smelter slag during molten oxidation. Metall. Mater. Trans. B 2015, 5, 2158-2164. [CrossRef]

9. Liu, H.L.; Hu, J.H.; Wang, H.; Wang, C.; Li, J.Q. Multiphase transformation during process of copper slag calcination. J. Cent. South Univ. 2013, 8, 3159-3165.

10. Zhang, G.F.; Yang, Q.R.; Yang, Y.D.; Wu, P.; McLean, A. Recovery of iron from waste slag of pyrite processing using reduction roasting magnetic separation method. Can. Metall. Q. 2013, 2, 153-159. [CrossRef]

11. Peng, N.; Peng, B.; Chai, L.Y.; Li, M.; Wang, J.M.; Yan, H.; Yuan, Y. Recovery of iron from zinc calcines by reduction roasting and magnetic separation. Miner. Eng. 2012, 35, 57-60. [CrossRef]

12. Li, G.H.; Gu, F.Q.; Jiang, T.; Luo, J.; Deng, B.N.; Peng, Z.W. Beneficiation of Aluminum-, iron-, and titanium-bearing constituents from diasporic bauxite ores. JOM 2017, 2, 315-322. [CrossRef]

13. Semykina, A.; Shatokha, V.; Sridhar, S. Innovative approach to recovery of iron from steelmaking slags. Ironmak. Steelmak. 2010, 7, 536-540. [CrossRef]

14. Wang, P.; Dong, F.Z. Research on Preparation of Iron Concentrate from Iron Tailings. In Proceedings of the 2010 International Symposium on Low-Carbon Economy and Technology Science, Zibo, China, 29-31 October 2010.

15. Ku, J.G.; Chen, H.H.; He, K.; Yan, Q.X. Force analysis and dynamic simulation of ferromagnetic mineral particles in magnetic separation process. J. Cent. South Univ. 2015, 5, 1577-1582.

(C) 2017 by the authors. Licensee MDPI, Basel, Switzerland. This article is an open access article distributed under the terms and conditions of the Creative Commons Attribution (CC BY) license (http:// creativecommons.org/licenses/by/4.0/). 